\title{
Enhancement of Fish Bioaccumulation Models with Environmental Geoinformatics
}

\author{
G. K. Luk, J. Nie and J. Li ${ }^{*}$ \\ Department of Civil Engineering, Ryerson University, 350 Victoria Street, Toronto, ON M5B 2K3, Canada
}

\begin{abstract}
This paper explores the advantages of applying Geographic Information Systems (GIS) in the mathematical modelling of fish toxins bioaccumulation. The method is demonstrated with a mercury contamination study for Lake Ontario's Rainbow Trout (Oncorhynchus mykiss). The paper reviews how the various GIS options for identifying and visualizing mercury contamination in the fish may be used to improve the accuracy and presentation of mathematical models. It is demonstrated that the integration of GIS with bioaccumulation models provides an improved investigation tool, which can overcome existing problems of regional zoning and data scattering. The perspectives of the study will provide an enhanced capability for data extension and interpolation in environmental modelling, achieving a higher level of accuracy unattainable before.
\end{abstract}

Keywords: Bioaccumulation, fish, geovisualization, GIS, Lake Ontario, mercury, models

\section{Introduction}

Recent research of high mercury concentrations in fish, particularly in lakes, has renewed concerns about the mercury in the environment (Beyer et al., 1996). Thousands of tonnes of mercury are released annually from industries and natural geological processes into the Great Lakes. Inorganic mercury is the general element released into lakes and the atmosphere from industries. However, it is readily converted to methyl mercury (MeHg) by microorganisms in the sediments, which is a more toxic form of mercury to fish and eventually becomes bioaccumulated in their bodies. Researchers have suspected that most or nearly all of the accumulated mercury in fish is in the form of MeHg (Latif et al., 2001).

When mercury is discharged into the water, bacteria convert it into MeHg, an organic form of mercury that is more readily accumulated by aquatic organisms. MeHg is also efficiently transferred up the food-chain to higher tropic levels until it reaches humans. Mercury contamination of fish is a serious problem for a large number of remote lakes in Canada, United States and Europe (Westcott and Kalff, 1996). The effect is long-term and cumulative, and due to the persistent nature of mercury, it may be magnified when passed up the food-chain in a process known as bioaccumulation. Human health concerns arise when fish and wildlife from these ecosystems are consumed by humans.

One of the most common approaches in assessing the mercury contamination problem in fish is through bioaccumulation models. Even though most of the existing fish bioaccumulation models require as input site-specific field environmental information, the model output is rarely interpreted with Geographic Information Systems (GIS) tech-

\footnotetext{
* Corresponding author: junli@ryerson.ca
}

niques. This is unfortunate given that many of the advances in GIS can be used effectively to promote the interpretation and understanding of the pollution problem. The objective of the paper is to demonstrate how the various GIS options for visualizing mercury contamination in the fish may be used to complement the results from mathematical models. The method will demonstrate, through an application to field data on a selected Lake Ontario fish species, that the incorporation of GIS data into bioaccumulation models will result in a much more powerful investigation tool. A direct comparison of the model results with and without the GIS interpretation shows the enhanced flexibility and accuracy that GIS can provide. It is envisaged that the innovative approach recommended in the paper will provide an enhanced capability for data extension and interpolation in environmental modelling.

\section{Surveillance Database}

As a measure to protect the health of those who consume sport fish, the Canadian government (Environment Canada) has been collecting fish samples from lakes and rivers throughout Canada for monitoring mercury contamination. The surveillance program spanned a period of seven years, and covered 345 locations from four of the five Great Lakes. In total, 16,384 individual samples were collected, from an area enclosed by $74.42-95.05^{\circ} \mathrm{W}$ in longitude and 41.83 $51.25^{\circ} \mathrm{N}$ in latitude. The samples comprised of 43 species of fish, collected from May 1992 to October 1998, with the observed mercury concentration ranging from 0.01 to $4.70 \mu \mathrm{g} / \mathrm{g}$. To demonstrate the type of information collected from the sampling, an excerpt of the database maintained by the surveillance program is given in Table 1.

Although the sampling consisted of 43 fish species collected from the four Great Lakes, only one species, Rainbow 
Table 1. Excerpt of Mercury-related Monitored Parameters

\begin{tabular}{|c|c|c|c|c|c|c|c|c|}
\hline Latitude & Longitude & Location & Species & Sampling Date & Length (cm) & Weight (g) & Sex & Mercury Conc. $(\mu \mathrm{g} / \mathrm{g})$ \\
\hline $44^{\circ} 06^{\prime} \mathrm{N}$ & $77^{\circ} 05^{\prime} \mathrm{W}$ & Lake Huron (NC2) & Yellow Perch & 26-Oct-98 & 29.6 & 400 & $\mathrm{~F}$ & 0.19 \\
\hline $44^{\circ} 06^{\prime} \mathrm{N}$ & $77^{\circ} 05^{\prime} \mathrm{W}$ & Lake Huron (NC2) & Yellow Perch & 26-Oct-98 & 30.5 & 400 & $\mathrm{~F}$ & 0.26 \\
\hline $44^{\circ} 25^{\prime} \mathrm{N}$ & $79^{\circ} 20^{\prime} \mathrm{W}$ & Lake Huron (NC2) & Yellow Perch & 26-Oct-98 & 33.0 & 490 & $\mathrm{~F}$ & 0.23 \\
\hline $44^{\circ} 06^{\prime} \mathrm{N}$ & $76^{\circ} 54^{\prime} \mathrm{W}$ & Balsam Lake & Rock Bass & 22-Oct-98 & 16.3 & 83 & $\mathrm{M}$ & 0.05 \\
\hline $44^{\circ} 06^{\prime} \mathrm{N}$ & $76^{\circ} 54^{\prime} \mathrm{W}$ & Balsam Lake & Rock Bass & 22-Oct-98 & 16.4 & 90 & M & 0.05 \\
\hline
\end{tabular}

Table 2. Summary of Sample Data of Rainbow Trout in the Great Lakes

\begin{tabular}{|c|c|c|c|}
\hline $\begin{array}{l}\text { Longitude } \\
\left({ }^{\circ} \mathrm{W}\right)\end{array}$ & $\begin{array}{l}\begin{array}{l}\text { Latitude } \\
\left({ }^{\circ} \mathrm{N}\right)\end{array} \\
\end{array}$ & Location & Samples \\
\hline \multicolumn{4}{|c|}{ Lake Ontario } \\
\hline 79.38 & 43.63 & Lake Ontario 4 & 1 \\
\hline 79.37 & 43.18 & $\begin{array}{l}\text { Lake Ontario 2a } \\
\text { Jordan H. }\end{array}$ & 20 \\
\hline 79.28 & 43.40 & Lake Ontario 2 & 5 \\
\hline 79.10 & 43.28 & $\begin{array}{l}\text { Lake Ontario } 2 \\
\text { Niagara Bar }\end{array}$ & 1 \\
\hline 79.05 & 43.12 & $\begin{array}{l}\text { Lake Ontario } 1 \mathrm{~b}- \\
\text { L. Niagara R. }\end{array}$ & 8 \\
\hline 78.67 & 43.83 & $\begin{array}{l}\text { Lake Ontario } 6 \\
\text { Northwestern }\end{array}$ & 14 \\
\hline 78.30 & 43.95 & $\begin{array}{l}\text { Lake Ontario } 7 \\
\text { Ganaraska }\end{array}$ & 100 \\
\hline \multicolumn{4}{|c|}{ Lake Huron } \\
\hline 83.07 & 46.10 & Lake Huron NC1 & 3 \\
\hline 82.95 & 45.75 & Lake Huron H1 & 7 \\
\hline 82.20 & 46.12 & $\begin{array}{l}\text { Lake Huron NC2 } \\
\text { McBean H. }\end{array}$ & 2 \\
\hline 82.03 & 43.20 & Lake Huron H5 & 20 \\
\hline 81.83 & 43.75 & Lake Huron H4 & 19 \\
\hline 81.32 & 44.57 & Lake Huron H3 & 9 \\
\hline \multicolumn{4}{|l|}{ Lake Erie } \\
\hline 81.12 & 42.62 & $\begin{array}{l}\text { Lake Erie } 2 \\
\text { Central Basin }\end{array}$ & 14 \\
\hline 80.17 & 42.67 & $\begin{array}{l}\text { Lake Erie } 3 \\
\text { Long Point B. }\end{array}$ & 6 \\
\hline \multicolumn{4}{|c|}{ Lake Superior } \\
\hline 89.40 & 48.10 & Lake Superior 1 & 25 \\
\hline 89.35 & 48.12 & $\begin{array}{l}\text { Lake Superior } 1 \\
\text { Jarvis B. }\end{array}$ & 15 \\
\hline 84.53 & 46.83 & Lake Superior 10 & 20 \\
\hline 84.52 & 46.72 & Lake Superior 11 & 11 \\
\hline 88.73 & 48.50 & Lake Superior 2 & 7 \\
\hline 88.42 & 48.83 & $\begin{array}{l}\text { Lake Superior } 4 \\
\text { Black Bay }\end{array}$ & 16 \\
\hline 88.42 & 48.80 & Lake Superior 5 & 29 \\
\hline 88.23 & 48.95 & $\begin{array}{l}\text { Lake Superior } 6 \\
\text { Nipigon }\end{array}$ & 36 \\
\hline 87.00 & 48.80 & Lake Superior 8 & 14 \\
\hline 86.38 & 48.73 & Lake Superior 8a & 10 \\
\hline 86.42 & 48.73 & $\begin{array}{l}\text { Lake Superior 8a } \\
\text { Penin.H. }\end{array}$ & 25 \\
\hline 86.40 & 48.73 & $\begin{array}{l}\text { Lake Superior 8a } \\
\text { Skin Is. }\end{array}$ & 20 \\
\hline 85.82 & 47.55 & Lake Superior 9 & 20 \\
\hline
\end{tabular}

Trout (Oncorhynchus mykiss), was selected and analysed to demonstrate the advantages of GIS to fish bioaccumulation studies in this paper. A total of 149 samples collected from the seven locations in the Lake Ontario were taken for demonstration in this study. Table 2 summarizes the sample data of Rainbow Trout collected from the selected seven locations in Lake Ontario, which are shown in Figure 1. The data are provided in Microsoft-Excel file format, and contain the fish length $(\mathrm{cm})$, weight $(\mathrm{g})$, mercury concentration $(\mu \mathrm{g} / \mathrm{g})$, location and gender, which can be displayed and edited by ArcView GIS 3x software package after they are converted into text file.

\section{Bioaccumulation Model}

The bioenergetics-based model, first proposed by Norstrom et al. (1976), and subsequently refined by Luk and Brockway (1997), is used in this study to examine the bioaccumulation behavior of sport fish in lakes. The concept of bioenergetics is based on an estimation of the various energy requirements of fish, for normal swimming and foraging activities as well as growth. A bioenergetics-based computer program, called the Generic Bioaccumulation Model (GBM) (Luk, 1996), simulating the bioaccumulation of MeHg in fish, was applied to provide an estimation of mercury levels for different species (Au-Yeung, 2002). It has been demonstrated that the GBM is a powerful tool in predicting the trends and magnitude of mercury levels among sport fish in Lake Ontario. It was found that factors such as age, size, metabolism, water temperature, gender, as well as mercury concentration and speciation in both water and diet, could influence the accumulation of mercury in fish. Moreover, a large number of samples are usually required to define mercury levels in a given aquatic community (Parks et al., 1994). As a result, a mathematical model incorporating field estimates of fish body size, growth rate, diet and mercury concentration in water is the best solution to examine the patterns in methyl mercury accumulation. Figure 2 demonstrates the relationship between the GBM and the various input parameters.

Figure 3 shows a sample simulation of Rainbow Trout as a function of weight. From the graph, it may be observed that there is an apparent "corner" in the simulation curve, occurring when the fish grows to around $1800 \mathrm{~g}$. This is a direct result of the discretization of the diet pattern of the fish in the program input. It was observed that as a fish grows, its diet changes from mostly phytoplankton and invertebrates when 


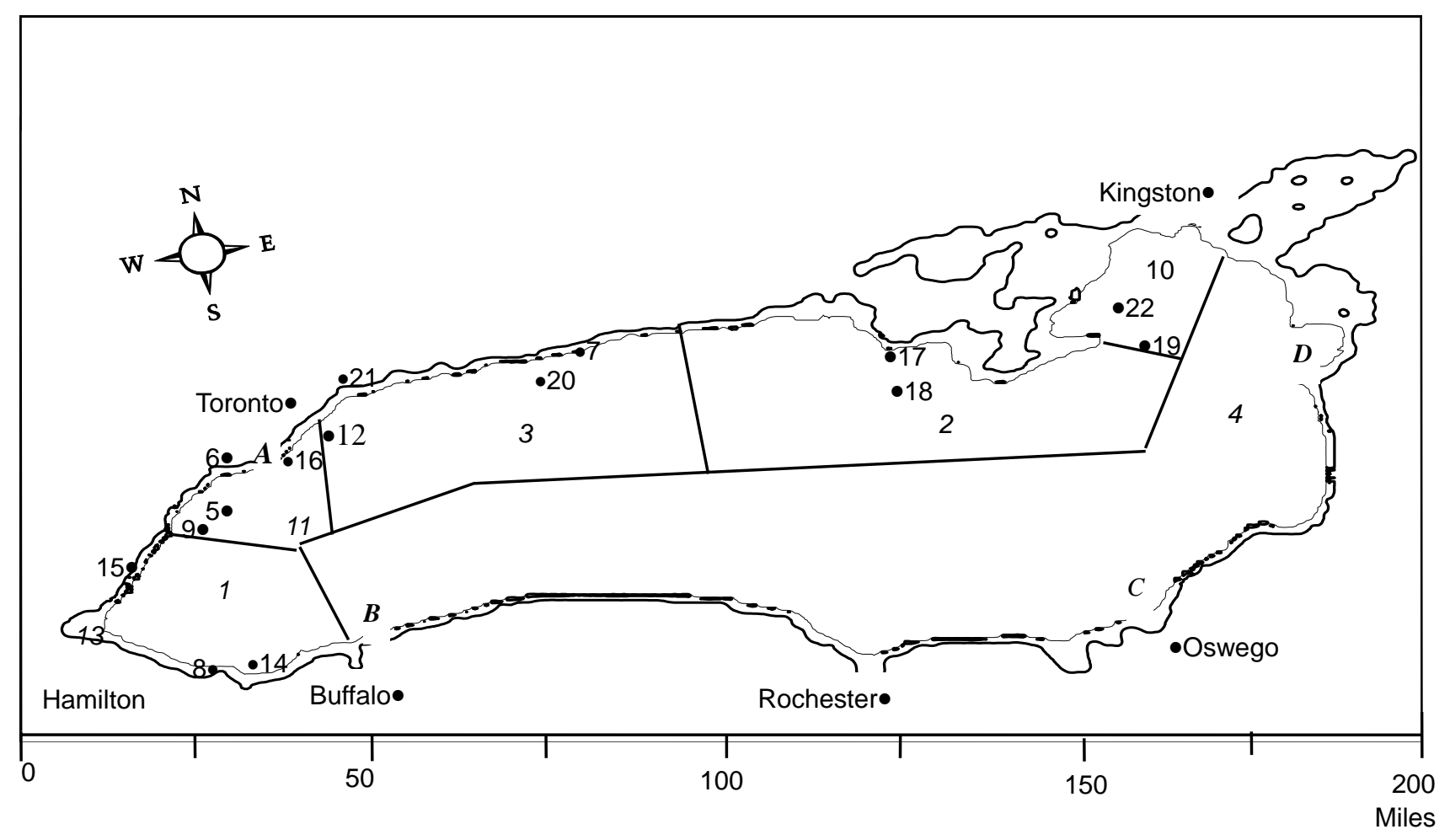

Copyright 1996 Underwater Technologies, Inc., all rights reserved Map Number NY310400 http://www.utmaps.com

Fish Sampling Sites:
1. Western Lake Ontario*
2. N.W. Lake Ontario*
6. Humber Bay
5. Credit River
10. L.Bay of Quinte
9. Marie Curtis River
14. Jordan Harbour
18. Scotch Bonnet
22. North Channel
3.N.E. Lake Ontario*
7.Ganaraska River
11.Toronto Offshore*
15.Bronte Creek
19.Main Duck Island
4.E. Lake Ontario*
8.Niagara Bay
12.Scarborough Bluffs
16.Ashbridges Bay
20.Port Hope
21. Bluffers Park

Water Quality Sampling Sites:
A.Toronto Harbour*
B.Niagara River*
C.Oswego River*
D. Black River Bay*

Note:

* represent regions; all others are specific sites.

Figure 1. Map of Lake Ontario demonstrating the location of fish and water quality sampling sites (Source: Environment Canada, Canada Centre for Inland Waters). 


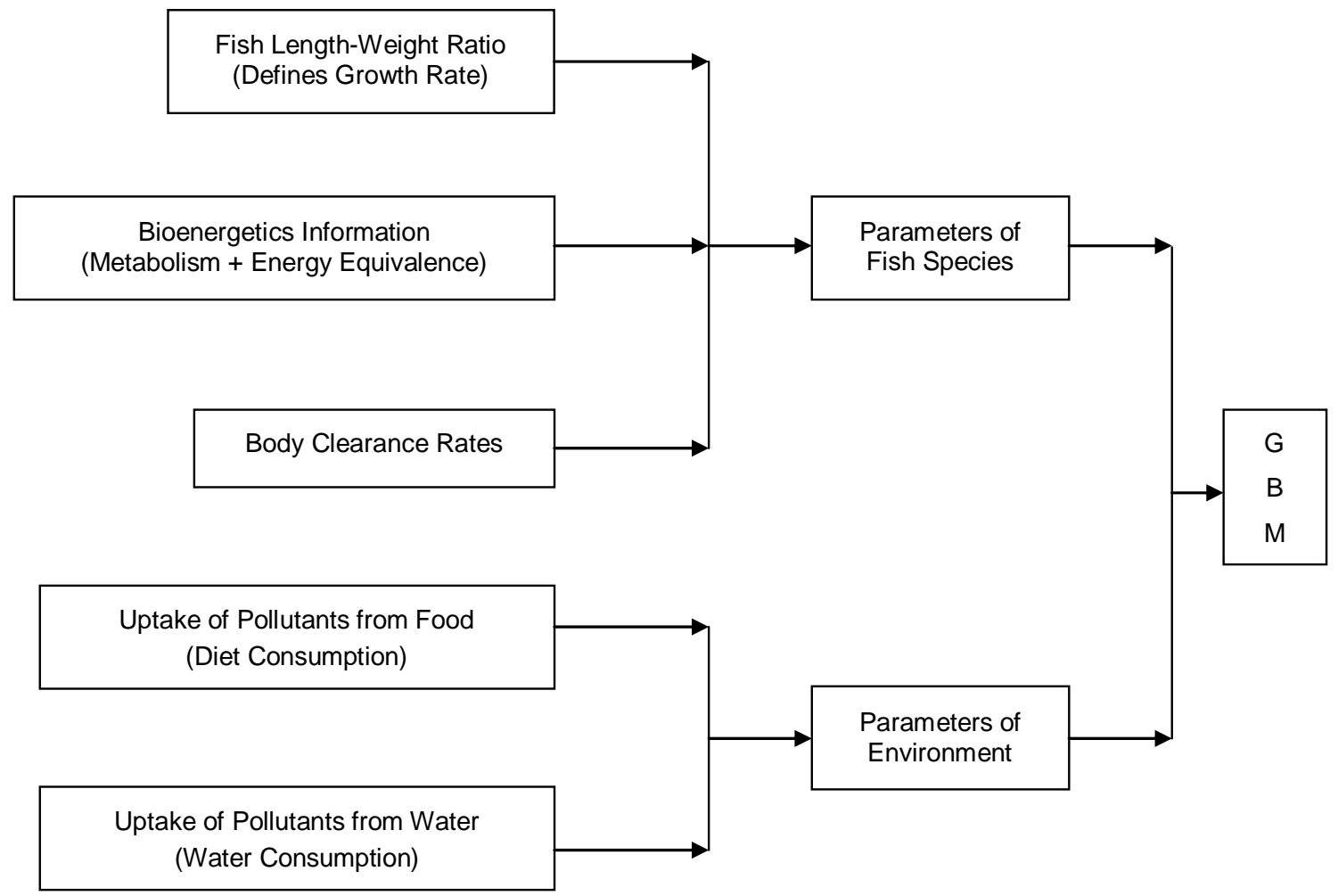

Figure 2. Relationship between the GBM and the input parameters.

the fish is small ( $<3$ years old in the case of rainbow trout), to crustaceans and small fishes after the fish matures. Even though the change occurs gradually in nature, the data input structure of the program will only accept discrete patterns for each age group. Therefore, the simulation will exhibit a segmented trend in the output, which can be corrected easily when more detailed discretization of the diet pattern is entered.

\section{Limitations of the GBM}

There are two major weaknesses associated with the approach of estimating MeHg levels using the GBM alone. First, it was observed that the MeHg concentration in fish depends heavily on the sampling location. Hence, the interpretation of the simulation results will only be meaningful if the data are divided into samples collected from different regions of the lake. Figure 4 shows the discrete data and linear trend lines of Lake Ontario's data as compared to those of the western region of the lake. It can be observed that the trend lines of the data are very different, even though the data from the western region is a subset of that of the whole lake. Therefore, the simulation of the MeHg bioaccumulation with the GBM should really be carried out in a region-by-region manner, and regions should be delineated based on similarity of the water environment, level of pollution and habitat characteristics, among other factors. The application of the geovisualization as well as spatial analysis tools in GIS will be extremely important for the modelling.

The second problem of most current applications of the GBM lies in the size of the study area. Theoretically, the GBM can handle a large study area, for instance, by using average values for the whole Lake Ontario in the present case. However, when the size of the study area is too large, an average value will not represent the lake conditions with any accuracy, and it becomes very difficult to assess the effectiveness of the model simulations due to data scatter. Such a limitation is demonstrated in Figure 5, where the lake-wide simulation curve is shown with the data taken from a selected region (in this case the western region) of the lake. It is clear that the simulated curve does not provide a good description of the trend of the bioaccumulation. The problem might be solved if the study area is broken down into several smaller regions, in which the data from each region are compared to a localized simulation. The use of GIS for spatial analysis and presentation of the data will allow a more accurate zoning system, by which the regions with similar fish concentrations could be identified and visualized effectively. 


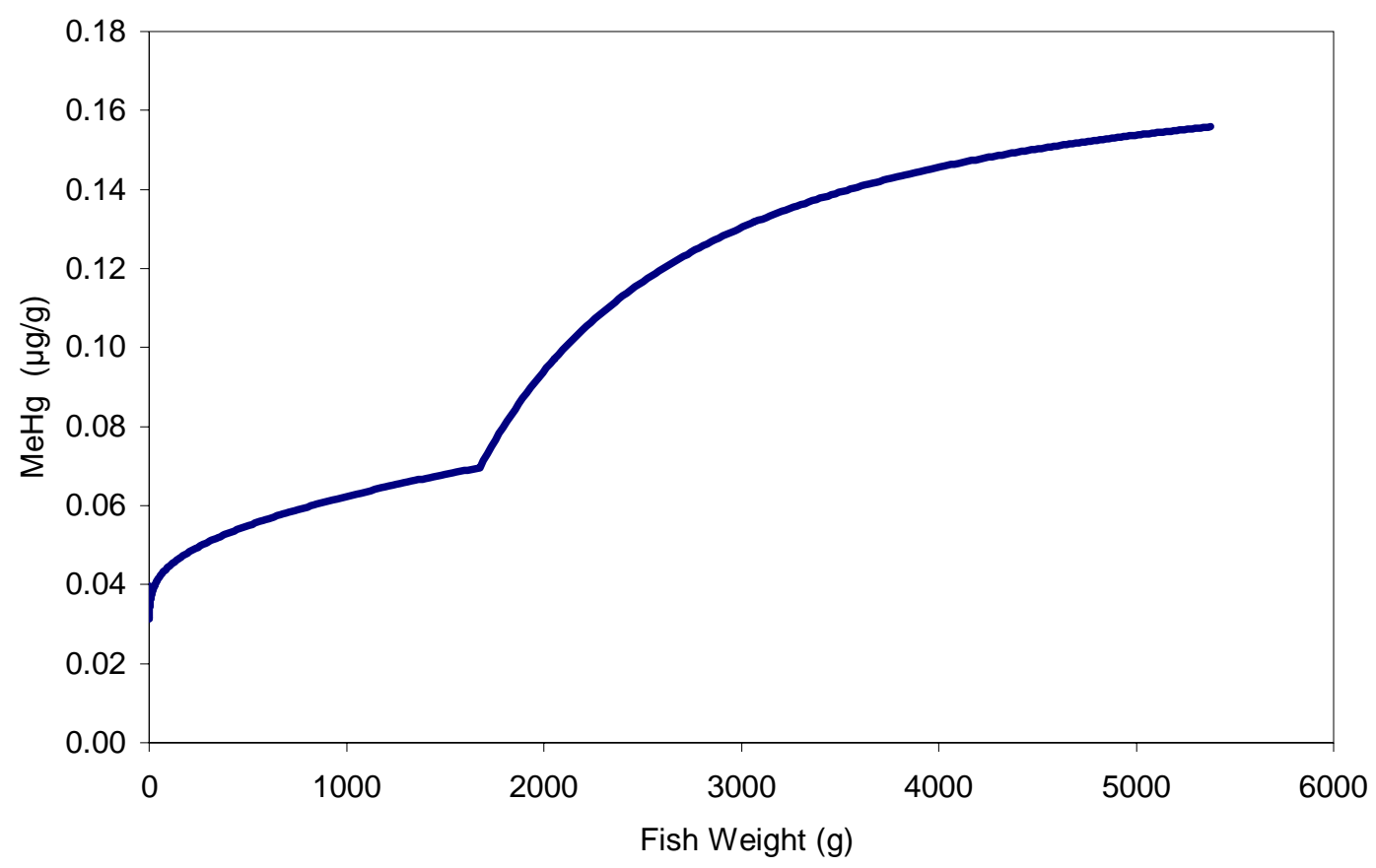

Figure 3. Mercury concentration of rainbow trout generated using the GBM.

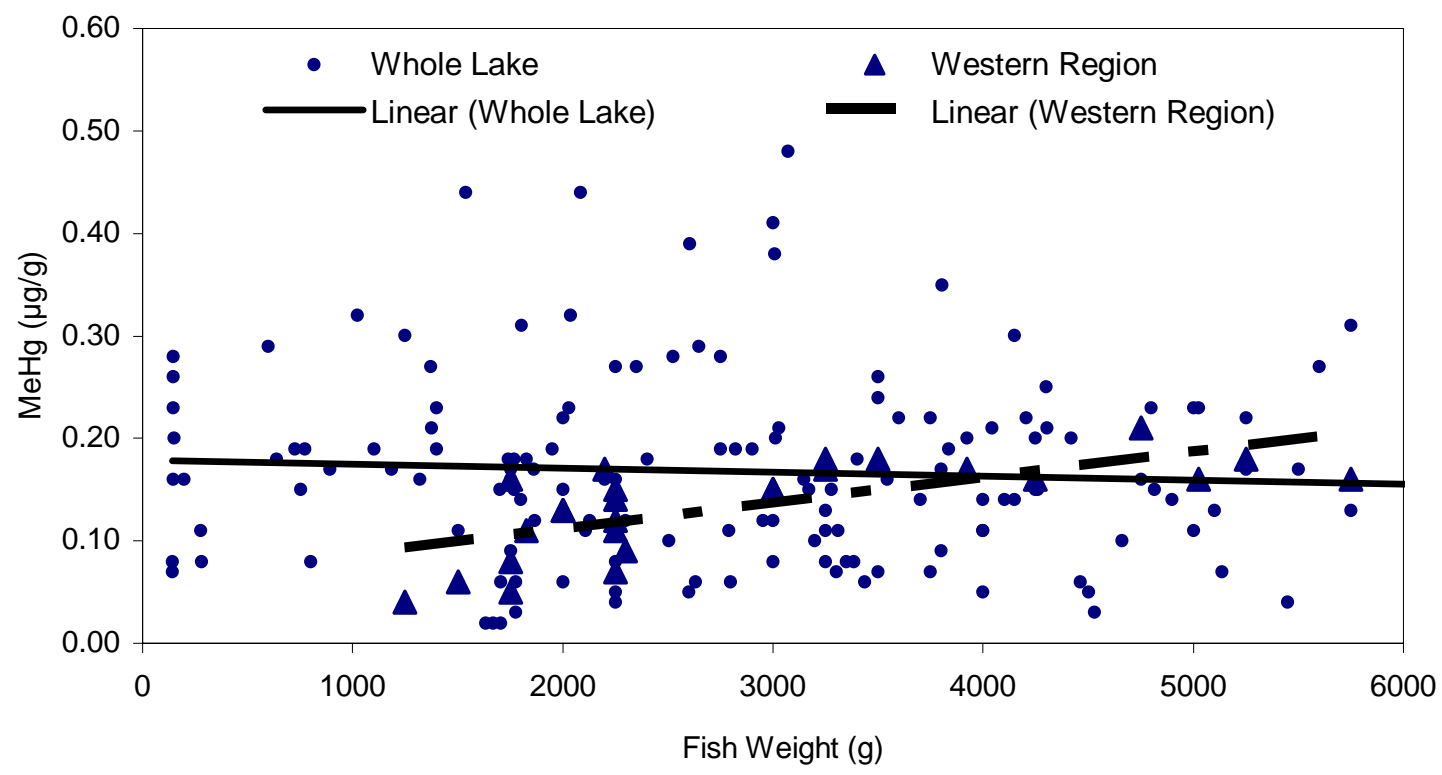

Figure 4. Data discrepancy with a large study area. 


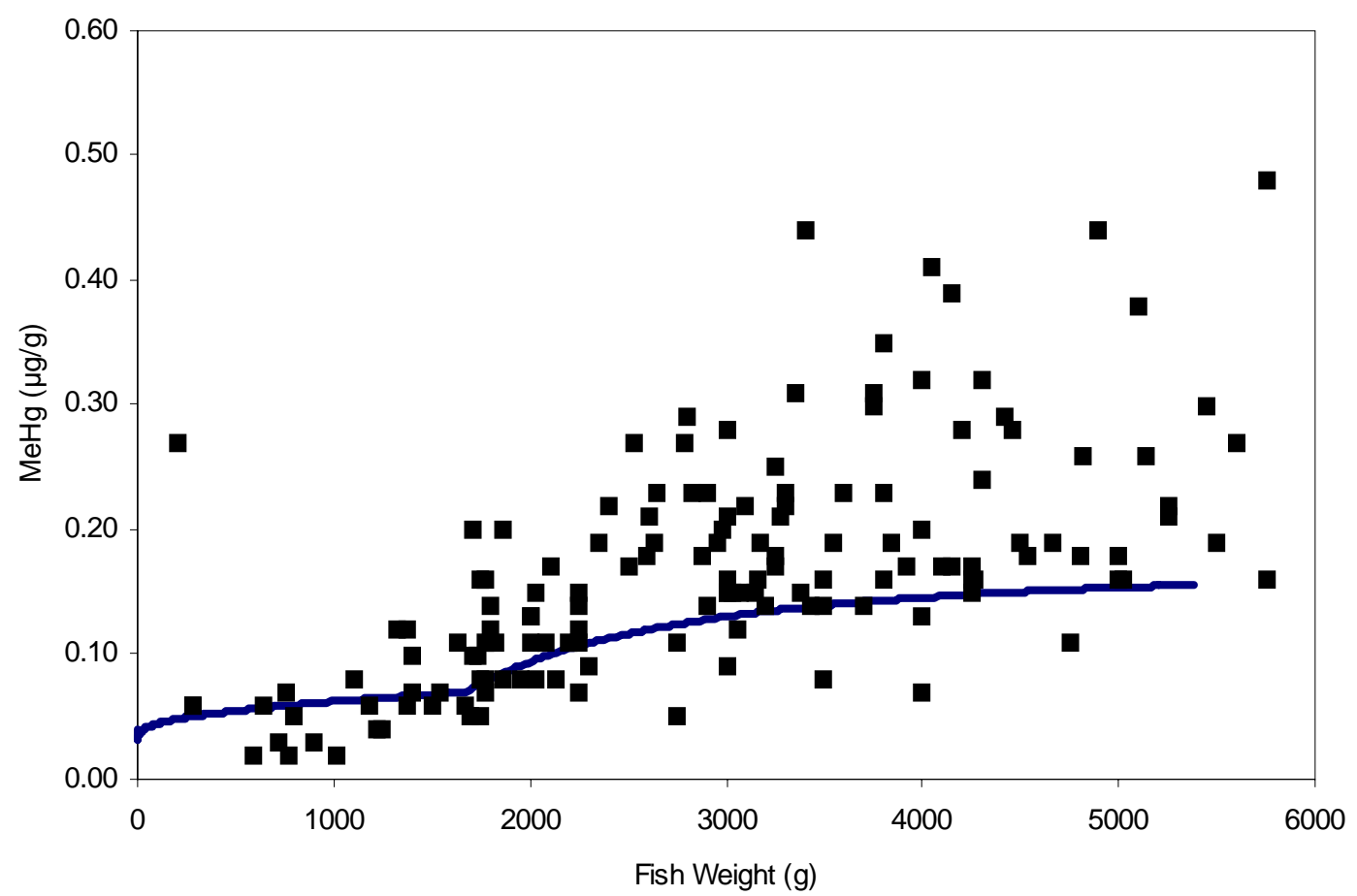

Figure 5. Limitation of the GBM with data scattering.

\section{Proposed GIS Approach}

This paper demonstrates the use of various GIS tools for analyzing mercury contamination to overcome the two limitations of the GBM mentioned above. For example, using ESRI's ArcView GIS Spatial Analyst extension, regional data for a particular species may be identified and analysed to define the regions of similar concentrations. This section uses sample data of Rainbow Trout collected in Lake Ontario to demonstrate how GIS enhances the GBM.

A total of 150 sample data of Rainbow Trout collected from Lake Ontario were used in this study. The first step of the proposed GIS approach is to define a subset of the database for the case study. With ArcView GIS, it is possible to obtain information on different features of any data entry by running the Spatial Analyst extension. Figure 6 shows the sample locations and regional designations of Lake Ontario with ArcView.

As discussed previously, aquatic conditions across Lake Ontario will not be consistent, and should not be modelled as such. Therefore, the second step of the proposed GIS approach is to define smaller study regions with similar environmental qualities within Lake Ontario. To accomplish this, the concentration values at all sampling points should be analyzed to provide continuous surfaces or regions with similar concentration values. This process of interpolation allows analysis on a limited number of points with known concentrations to come up with estimated values for all locations in the lake. At this point, the "Interpolate Grid" function from the "Surface" menu may be selected to define the regions within the lake with similar concentrations. In this example, four elevation surfaces are generated from the interpolation, namely Regions I, II, III and IV, which are illustrated with the mercury concentration ranges shown in Figure 6.

It can be seen that with GIS it becomes much more convenient to focus on any given region for bioaccumulation modelling. For instance, detailed environmental conditions of Region II were obtained and entered as input into the GBM. The results of the simulation are then compared to the data obtained from the sampling points in Region II. Figure 7 compares measured fish concentrations with regionally predicted ones. As may be observed from Figure 7, a more accurate simulation with less scatter than the use of GBM alone is obtained with the GIS approach, although the same GBM was used in the analysis.

\section{Comparison of the Results and Discussion}

The effectiveness of applying GIS to fish contamination modelling may be further explored when the results of the regional GBM simulation are shown alongside the original Lake Ontario database. Figure 8 shows the GMB bioaccumulation simulation for Lake Ontario Region II, as compared to the field data and data trend of the entire lake, whereas Figure 9 shows the same simulation as compared to the Region II data and trend. Even though the simulation results are 


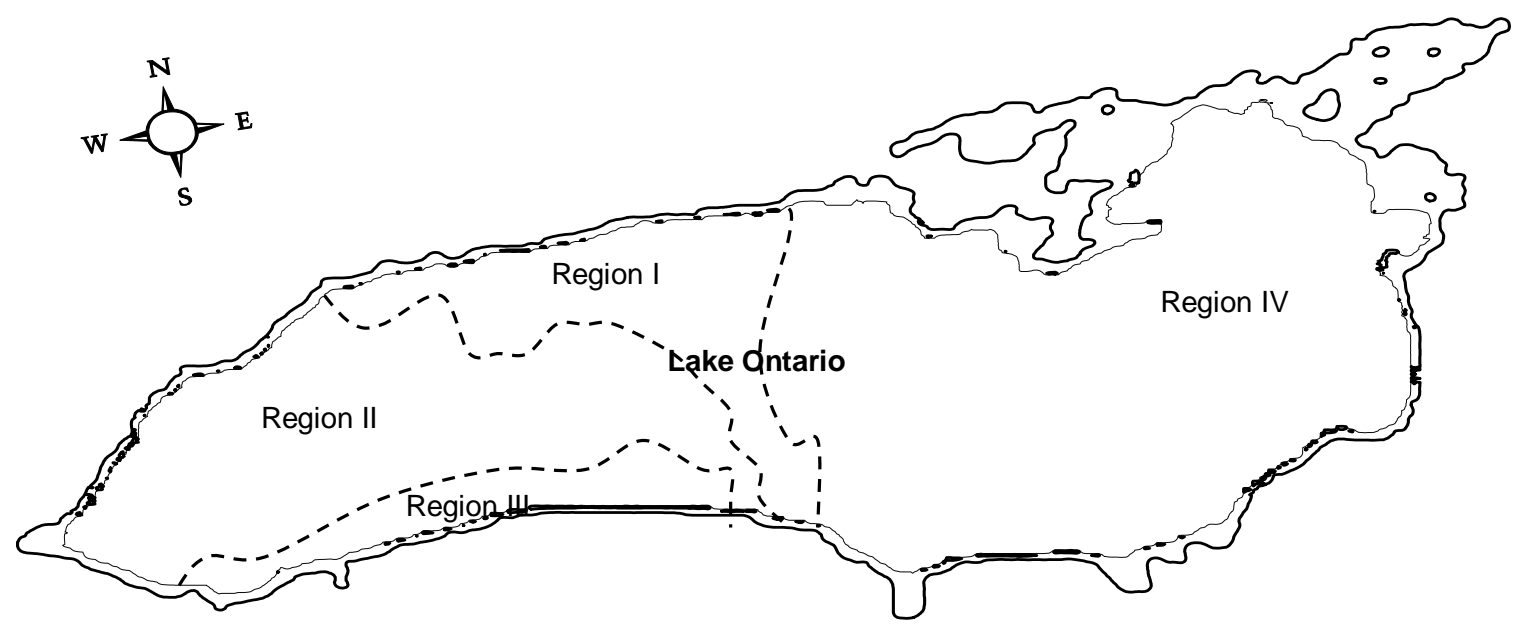

Copy right 1996 Underwater Technologies, Inc., all rights reserved Map Number NV310400 http://www.utmaps.com

Figure 6. Sample locations and regional designations of Lake Ontario.

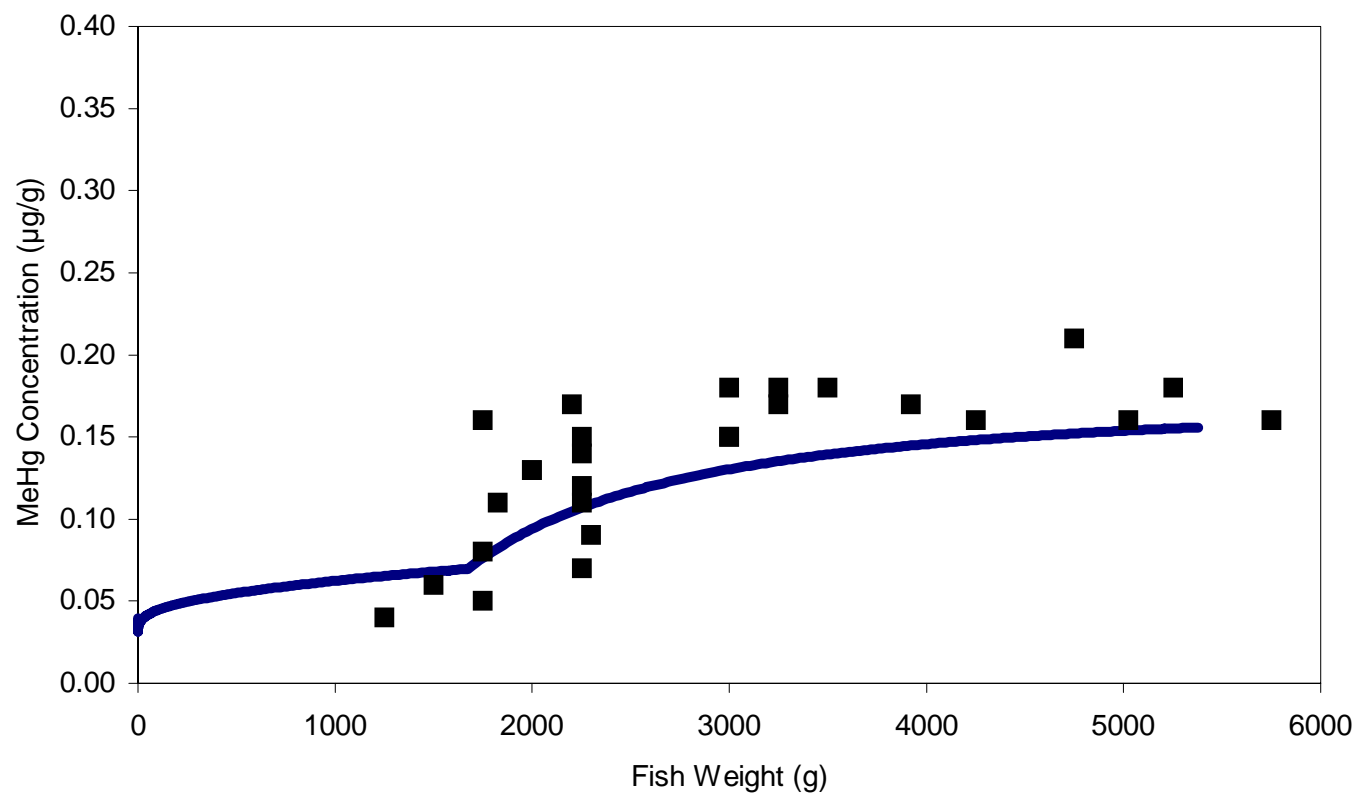

Figure 7. MeHg concentrations of Rainbow Trout in Region II of Lake Ontario. 


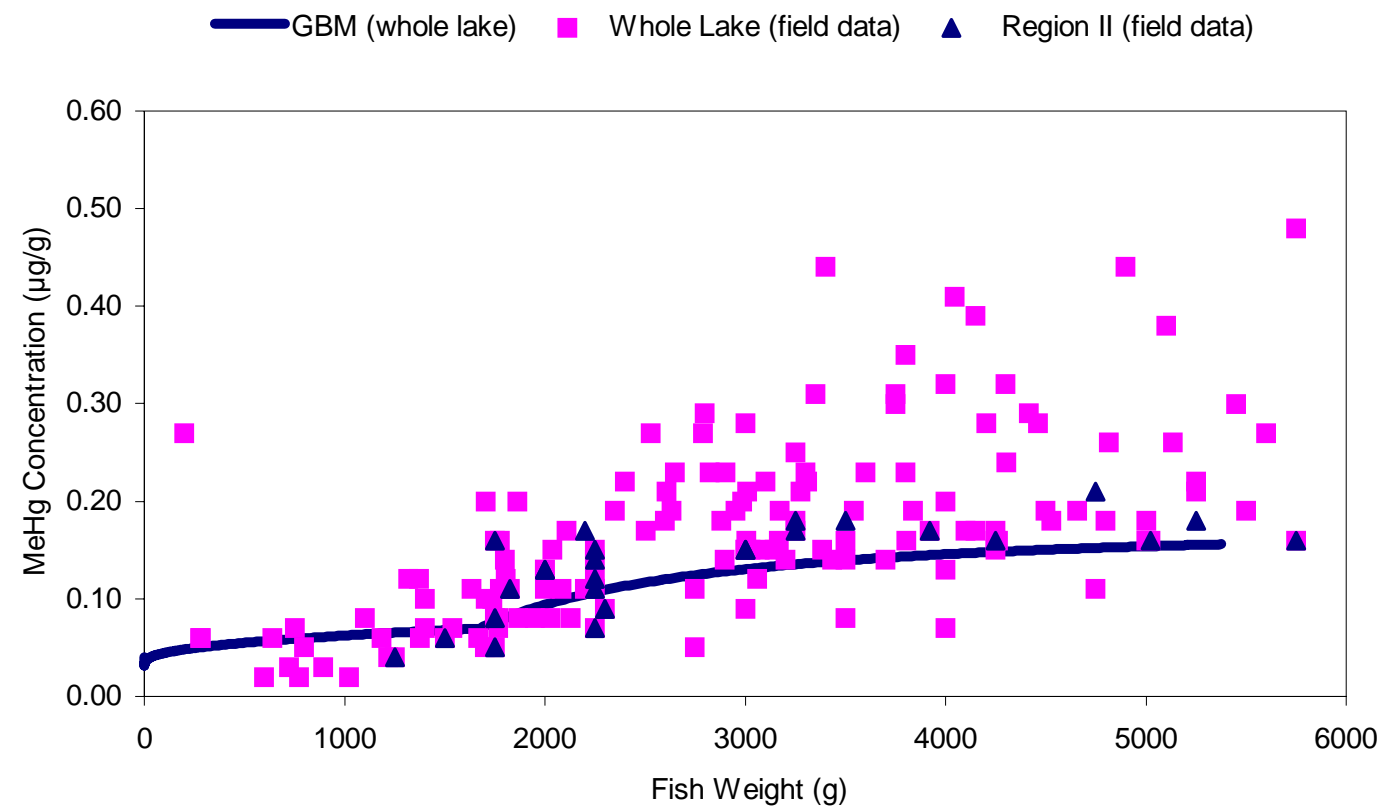

Figure 8. GMB simulation of Region II compared to the whole lake data.

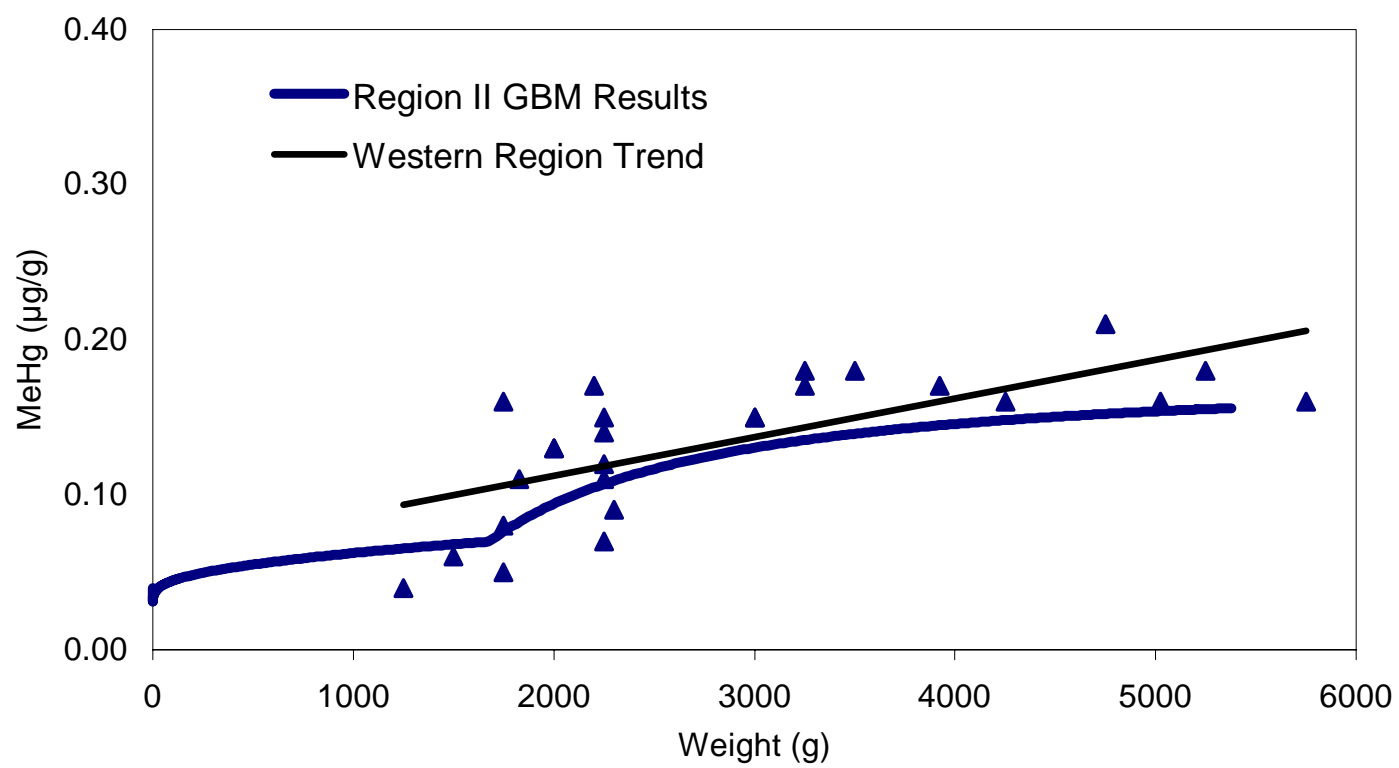

Figure 9. GMB simulation of Region II compared to the western region data. 
reasonably close to those of the data in the first figure, it can clearly be observed that a much improved accuracy is obtained from the second figure. This is also demonstrated by the substantial improvement in the sum-of-residuals $\left(\mathrm{R}^{2}\right)$ values of the two plots, from an initial value of 0.63 to a much improved value of 0.90 . Therefore, it is demonstrated that with GIS, a much more accurate simulation may be achieved with the same bioaccumulation model framework. It should also be noted that with just a single use of GIS, it becomes possible to model regional trends of $\mathrm{MeHg}$ bioaccumulation for all of the different areas of the entire lake. Obviously, the resolution and delineation of the regions will depend heavily on the availability of the data, and with a more extensive database, it will be possible to divide the lake into smaller regions to obtain better simulation of the concentrations.

The process of mathematical modelling often revolves around some trial-and-error effort, and in some cases its predictive power, accuracy, and relation to reality might be a research problem of its own. Most models are developed based on some simplified assumption of the actual processes, with the aid of observations and statistical analysis of observed data. Therefore, their applicability is often limited to the conditions for which they were developed. Some existing models, however, may have a very sound theoretical framework and stand up to more rigorous verifications than the others. For example, the GBM used in this study has been applied to examine the bioaccumulation behavior of $\mathrm{MeHg}$ in many different species of fish in Lake Ontario with some success. Even so, much of the concept of bioenergetics, based on the energy requirements of fish during different phases of their lives, is at best a very approximate reflection of reality. This approach provides an approximate picture of the phenomenon of MeHg bioaccumulation, but lacks accuracy because it fails to take into account all the local environmental and habitat effects. GIS provides an impressive improvement to the GBM results, by its powerful spatial analysis and visualization functions. Spatial analysis is used to estimate measured data to the nodes in grids that do not coincide with measured points. Based on the generated estimated and measured concentrations, specific regional concentrations can be generated. As demonstrated by the Region II study in this paper, the delineation can provide a substantial improvement on the accuracy of the simulation results generated from the same model. Naturally, there is some limitation on the interpolation process, and caution should be applied to ensure that reasonable estimates are obtained from the input data and density of measurements.

It should be noted that when approaching any new project involving environmental data analysis and visualization, the first step is to assess the form and content of the data. Data are commonly delivered in many forms. A visual assessment of the content of the data is just as useful as evaluating basic summary statistics, such as the number of samples, minimum, average, and maximum data value, as well as the spatial extent. The form of the data is usually governed by the application in which the data were authored or stored. For this study, the database has been stored in a spreadsheet program. It is generally accepted that visualization is an important means for condensing and effectively communicating vast quantities of spatially referenced data (Fisher, 1993). It provides an invaluable tool to communicate complex data in a form that makes the data universally intelligible. Direct visualization of field data requires only moderate amount of interpretation or assumption. ArcView has a powerful extension function of "gridding" the data, so that interpolation (and extrapolating) of the data may be applied to the nodes and/or cells of the grid. This, when combined with the incorporation of geographic information site features, enables the user to present the data visually using different representation methods. As demonstrated by the results of this study, the integration of GIS with bioaccumulation models would resolve the issues of scattering and inaccuracy typically encountered in most mathematical models, resulting in a powerful investigation not possible with the application of either one.

\section{Concluding Remarks}

One of the key challenges in environmental research is the description of interacting physical processes with sufficient realism (e.g., Clarke et al., 2001). It is clear that the rapid advances in GIS technology offer new opportunities to tackle extremely complex environmental modelling problems.

Most of the existing fish bioaccumulation models require site-specific environmental information as input, and meaningful interpretation of the model performance is only possible when the data collected are also presented in a clear geovisualization format. This study reviews how GIS is used for spatial analysis and visualization of mercury contamination in fish that may be used to assess and improve the results of mathematical models. It is demonstrated that the integration of GIS with bioaccumulation models will result in a more powerful investigation tool, for a comprehensive analysis and presentation of the pollution problem. The perspectives of the study will provide an enhanced capability for regional data definition and interpolation in environmental modelling, especially for some locations where direct sampling is not feasible. This approach will also help to refine the process of parameter calibration, so that more realistic and localized values may be obtained with the present formulation of the model based even on limited data.

In conclusion, GIS can play an important role in contaminant modelling because of the many advantages it offers over traditional environmental modeling methods. Spatial modelling and map creation can be done on the same system, and the mathematical models can be assessed by using real data collected and arranged by GIS tools. Finally, the combination of GIS methods with bioaccumulation model can address the spatial distribution of mercury level in the Great Lakes fish, and assist the identification of regions and locations where preventive and control measures are most needed.

Acknowledgments. The authors are grateful to the Environment Canada for the permission to use the surveillance data in the demonstra- 
tions of this paper. The technical assistance of Amy Au-Yeung is also greatly appreciated. The authors would also like to thank the anonymous external reviewers for their invaluable insights to improve the paper.

\section{References}

Au-Yeung, W.C. (2002). Methyl Mercury Bioaccumulation in Sport Fish and the relation to Human Exposure, M.Sc. Dissertation, Ryerson University, Toronto, ON, Canada.

Beyer, W.N., Heinz, G.H. and Redmon-Norwood, A.W. (1996). Environmental Contaminants in Wildlife-Interpreting Tissue Concentrations, Lewis Publishers Inc., New York.

Clarke, K.C., Parks, B.O. and Crane, M.P. (2001). Visualizing environmental data, Geographic Information Systems and Environmental Modelling, Prentice Hall, Upper Saddle River, New Jersey, pp. 252-287.

Fisher, T.R. (1993). Use of 3D Geographic Information Systems, in G. Wadge, A.P. Wislocki and E.J. Pearson (Eds.), Hazardous Waste Site Investigations: Environmental Modeling with GIS, Oxford University Press, pp. 238-247.
Latif, M.A., Bodaly, R.A., Johnston, T.A. and Fudge, R.J.P. (2001). Effects of environmental and maternally derived methylmercury on the embryonic and larval stages of walleye (Stizostedion vitreum). Environ. Pollut., 111, 139-148.

Luk, G.K. and Brockway, F. (1997). Application of a polychlorinated biphenyls bioaccumulation model to Lake Ontario lake trout. Ecol. Model., 101, 97-111.

Luk, G.K. (1996). PCB Bio-Accumulation Program Version 1996, Civil Engineering Department, Ryerson Polytechnic University, Toronto, Ontario, Canada.

Norstrom, R.J., McKinnon, A.E. and DeFreitas, A.S.W. (1976). A bioenergetics-based model for pollutant accumulation by fish, simulation of PCB and methylmercury residue levels in Ottawa River Yellow Perch (Perca flavescens). J. Fish Resour. Board Can., 33, 248-267.

Parks, J.W., Craig, P.C. and Azburn, G.W. (1994). Relationships between mercury concentrations in walleye (Stizostedion vitreum) and northern pike (Esox lucius): Implication for modelling and biomonitoring. Can. J. Fish. Aquat. Sci., 51, 2090-2104.

Westcott, K. and Kalff, J. (1996). Environmental factors affecting methylemercury accumulation in zooplankon. Can. J. Fish. Aquat. Sci., 53, 2221-2228. 